\title{
Poly(A) elongation during Xenopus oocyte maturation is required for translational recruitment and is mediated by a short sequence element
}

\author{
L. Lynn McGrew, ${ }^{1}$ Eva Dworkin-Rastl, ${ }^{2}$ Mark B. Dworkin, ${ }^{2}$ and Joel D. Richter ${ }^{1}$ \\ ${ }^{1}$ Worcester Foundation for Experimental Biology, Shrewsbury, Massachusetts 01545 USA; ${ }^{2}$ Ernst-Boehringer-Institut, A-1121 \\ Vienna, Austria
}

Xenopus oocytes contain several mRNAs that are mobilized into polysomes only at the completion of meiosis (maturation) or at specific times following fertilization. To investigate the mechanisms that control translation during early development, we have focused on an mRNA, termed G10, that is recruited for translation during oocyte maturation. Coincident with its translation, the poly(A) tail of this message is elongated from $\sim 90$ to 200 adenylate residues. To identify the cis sequence that is required for this cytoplasmic adenylation and recruitment, we have synthesized wild-type and deletion mutant G10 mRNAs with SP6 polymerase. When injected into oocytes that subsequently were induced to mature with progesterone, wild-type G10 mRNA, but not mutant transcripts lacking a 50-base sequence in the $3^{\prime}$-untranslated region, was polyadenylated and recruited for translation. The 50-base sequence was sufficient to confer polyadenylation and translation when fused to globin mRNA, which does not normally undergo these processes during oocyte maturation. Further mutational analysis of this region revealed that a U-rich sequence $5^{\prime}$ to the AAUAAA hexanucleotide nuclear polyadenylation signal, as well as the hexanucleotide itself, were both required for polyadenylation and translation. The 50-base cis element directs polyadenylation, but not translation per se, as a transcript that terminates with $3^{\prime}$-deoxyadenosine (cordycepin) is not recruited for translation. The available data suggest that the dynamic process of polyadenylation, and not the length of the poly(A) tail, is required for translational recruitment during oocyte maturation.

[Key Words: Xenopus oocyte; poly(A); meiosis; oogenesis]

Received January 4, 1989; revised version accepted April 3, 1989.

Early embryonic development in several animals is programmed by mRNAs that are present in the egg at the time of fertilization (Smith and Richter 1985; Davidson 1986). Many of these maternal mRNAs are synthesized throughout oogenesis, but are not translated until oocytes resume meiosis (maturation) or are subsequently fertilized. In Xenopus, for example, the transcripts encoding the core histones (Adamson and Woodland 1977) and the proto-oncogene c-mos (Sagata et al. 1988) among others (Smith et al. 1988a; for review, cf. Richter 1987) all enter polysomes from a nontranslating compartment during oocyte maturation. Other mRNAs, such as those encoding histone $\mathrm{Hl}$ (Woodland et al. 1979; Flynn and Woodland 1980), fibronectin (Lee et al. 1984), and lamin (Stick and Hausen 1985), remain quiescent during these periods, and enter polysomes later in embryogenesis. A third class of maternal transcripts, exemplified by ribosomal protein L1, is translated in oocytes but is repressed during maturation (Baum et al. 1988; Hyman and Wormington 1988). These observations indicate that several mechanisms control the expression of maternal mRNA.

One of these modes of translational control appears to be the availability of a factor(s) that limits the amount of message that can be assembled into polysomes. This was inferred from experiments that show that although mRNA injected into Xenopus oocytes or into sea urchin eggs is translated, it is accompanied by a reciprocal decrease in the translation of endogenous mRNAs (Laskey et al. 1977; Asselbergs et al. 1979; Richter and Smith 1981; Collin et al. 1987). Candidates for the factor that limits overall translation include eukaryotic initiation factor 4A (eIF-4A) in Xenopus oocytes (Audet et al. 1987) and eIF-4F in sea urchin eggs (Huang et al. 1987). It seems unlikely, however, that these factors could discriminate between different mRNAs to such an extent that they could account for all of the differential mRNA translation that takes place in early development. Therefore, other mechanisms must control the translation of specific mRNAs, one of which appears to be repressor proteins. In this case, it is envisioned that mRNAs are bound by proteins that inhibit translation, which degrade or dissociate from the transcripts when they are to enter polysomes (Spirin 1969; Jenkins et al. 1978; Richter and Smith 1984; Crawford and Richter 1987; Grainger and Winkler 1987; Kick et al. 1987; Swi- 

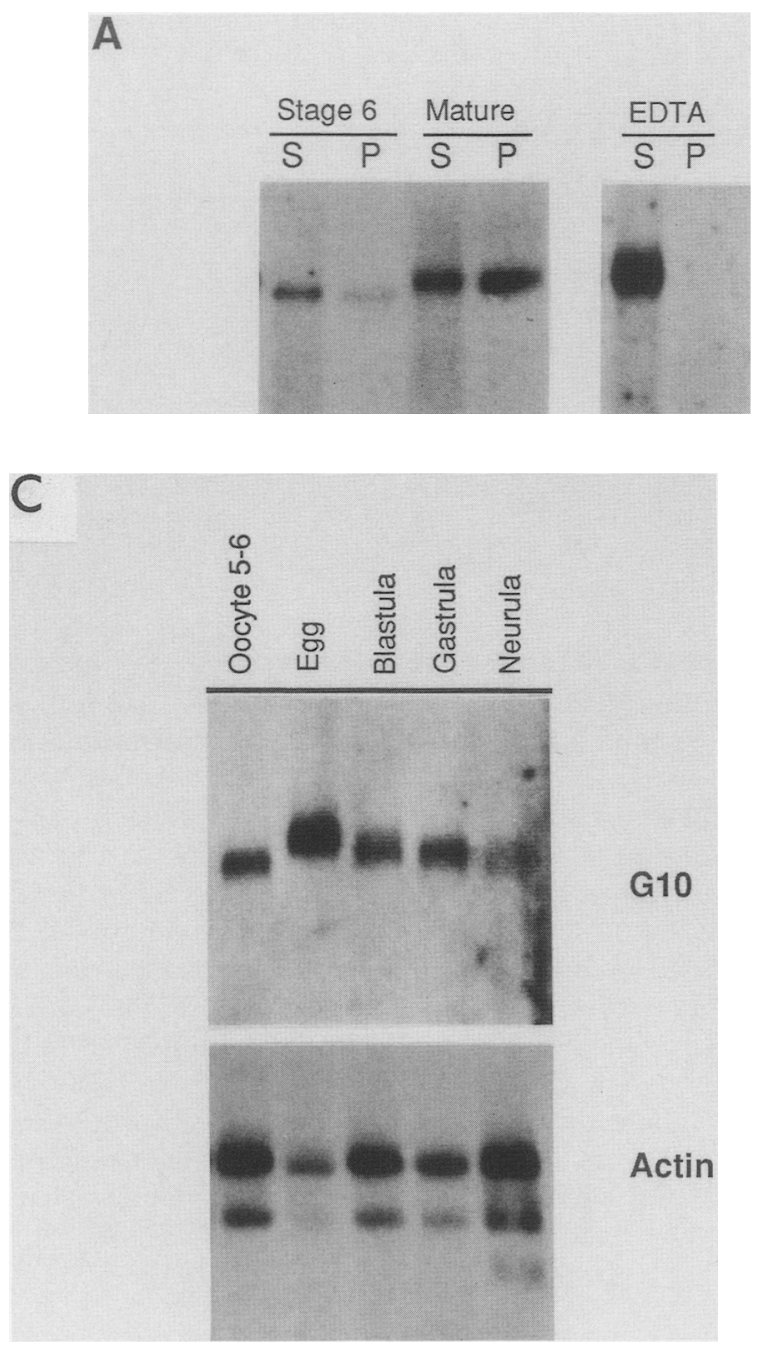

derski and Richter 1988; for review, see Richter 1987; Rosenthal and Wilt 1987).

Changes in the primary structure of maternal mRNA may also be important for translational regulation during early development. Following oocyte maturation in Xenopus and fertilization in several marine invertebrates, a specific subset of maternal poly $(A)^{+}$mRNA undergoes a size increase that is due to polyadenylation (Colot and Rosbash 1982; Rosenthal et al. 1983; Dworkin and Dworkin-Rastl 1985; Rosenthal and Wilt 1986; for review, see Rosenthal and Wilt 1987). Although many of these messages also enter polysomes at these times, it is unclear whether translation requires adenylation or whether these two processes merely coincide temporally but are functionally unrelated. In addition, the cis elements that are important for adenylation and/or translation of these mRNAs have not been identified. In our investigations, we have defined a 50nucleotide cis element at the 3 ' end of a Xenopus oocyte maternal mRNA that is necessary and sufficient for both polyadenylation and translation during oocyte maturation. Within this element reside two sequences, UUUUUUAU and AAUAAA, which are both required

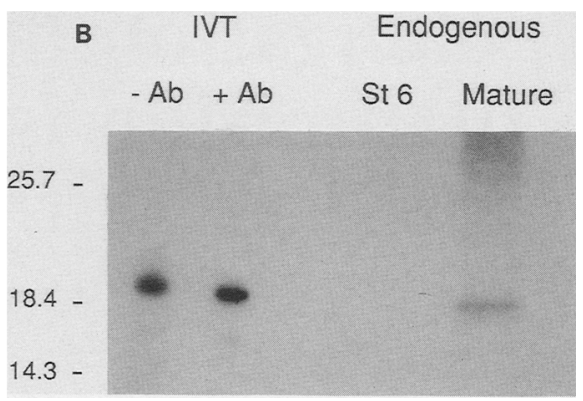

Figure 1. Gel blot analysis of G10 RNA during early development. (A) Stage-6 (control) and progesterone-matured (mature) oocytes were homogenized, centrifuged through $35 \%$ sucrose, and the RNA extracted from the polysomal pellet $(\mathrm{P})$ and the postpolysomal supernatant (S). The RNA was then analyzed by a gel blot probed with nick-translated G10 cDNA. A group of mature oocytes was also homogenized and centrifuged in solutions that contained $20 \mathrm{~mm}$ EDTA. The RNA was processed as described above. $(B)$ SP6-derived G10 mRNA was translated in a reticulocyte lysate supplemented with $\left.{ }^{35} \mathrm{~S}\right]$ methionine (IVT). Newly synthesized G10 protein was then examined without further purification $(-\mathrm{Ab})$, or following immunoprecipitation (+Ab). G10 protein was also immunoprecipitated from control and mature oocytes that were injected with $\left[{ }^{35} \mathrm{~S}\right]$ methionine. All proteins were resolved on an SDS-15\% polyacrylmide gel followed by autoradiography. $(C)$ One microgram of poly $(\mathrm{A})^{+}$ RNA from oocytes and embryos of several developmental stages was probed on a gel blot with nick-translated G10 cDNA. These same RNA samples were also probed with a cDNA encoding Xenopus actin.

for these processes. We also show that polyadenylation and translation are blocked if the message $3^{\prime}$ terminus is modified to contain cordycepin. These data suggest that the process of polyadenylation is required for mRNA recruitment during oocyte maturation.

\section{Results}

\section{Characterization of maternal G10 mRNA}

Oocyte maturation in Xenopus is accompanied by the recruitment of specific maternal mRNAs into polysomes. An example of one such mRNA that is mobilized at this time is G10, which was cloned from an oocyte cDNA library (Dworkin et al. 1985). To study G10 mRNA translation, its distribution between polysomal and nonpolysomal fractions was analyzed in fully grown but immature stage- 6 oocytes, and stage- 6 oocytes induced to mature in vitro with progesterone. Oocytes were homogenized, centrifuged through $35 \%$ sucrose, and the RNA was extracted from the pellet, which contains polysomes, and the supernatant, which contains nontranslating mRNAs. A Northern gel blot probed with nick-translated G10 cDNA is shown in Figure 1A. 
In stage- 6 oocytes, $\sim 16 \%$ of G10 mRNA was found in the pellet fraction whereas in mature oocytes, this amount increased to $>60 \%$. This demonstrated that G10 mRNA enters polysomes from a nontranslating compartment in response to progesterone. As a control, homogenates from mature oocytes were also centrifuged through sucrose that contained EDTA, which dissociates the ribosomes from the mRNA. In this case, no G10 sequences were found in the pellet. It is also evident from Figure 1A that G10 mRNA increases in size following maturation, which indicates that some structural modification accompanies its assembly into polysomes.

We have confirmed that polysomal recruitment of G10 mRNA during maturation does indeed lead to the production of G10 protein. Control and mature oocytes were injected with $\left[{ }^{35}\right.$ S]methionine followed by immunoprecipitation of G10 protein using a rabbit polyclonal antibody directed against a G10- $\beta$-galactosidase fusion protein. For comparison, G10 protein synthesized in a reticulocyte lysate from an SP6-derived G10 mRNA (see below) was also immunoprecipitated. Figure 1B shows that G10 synthesis in stage-6 (control) oocytes was virtually undetectable. Following maturation, the synthesis of G10 protein was observed clearly. Therefore, these data agree with the polysome isolation experiments which demonstrate that G10 mRNA is translated predominantly during oocyte maturation.

The steady-state levels of G10 mRNA were examined during early development. Figure $1 \mathrm{C}$ shows a gel blot of poly $(A)^{+}$RNA isolated from stage- 5 and stage- 6 oocytes, shed eggs, blastulae ( $7 \mathrm{hr}$ postfertilization), gastrulae (12 $\mathrm{hr}$ postfertilization), and neurulae (19 hr postfertilization) probed with labeled G10 cDNA. Although the mass of G10 mRNA stays relatively constant throughout early development, it is clear that this transcript is modified in the egg, as seen by a slower electrophoretic

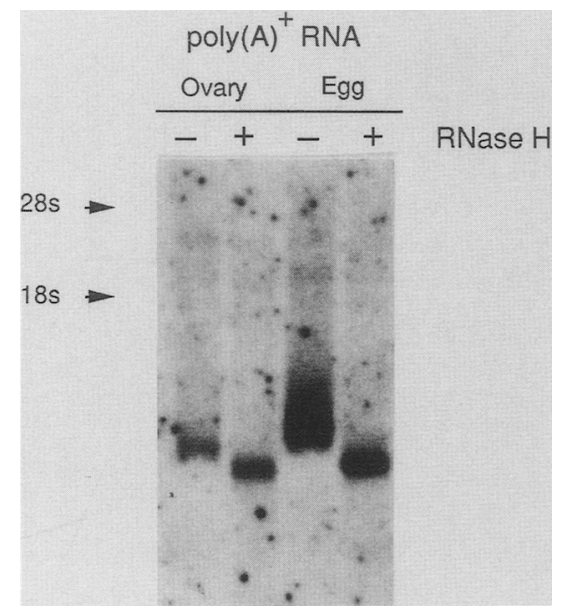

Figure 2. Assessment of poly(A) tail length of G10 mRNA. One microgram of poly $(\mathrm{A}))^{+}$RNA from total ovary and shed eggs was hybridized to oligo(dT) and then incubated in the absence $(-)$ or presence $(+)$ of RNase $H$. The products were then analyzed by a gel blot probed with radiolabeled G10 cDNA. Ribosomal RNA (18S and 28S) markers are noted. migration rate. G10 mRNA is further modified in the early embryo, but in this case, its migration rate increases rather than decreases. For comparison, the same RNA probed with actin cDNA demonstrates that these transcripts do not have an altered electrophoretic mobility.

Several investigators have shown that there is considerable processing of poly(A) during the early development of several species (for review, see Rosenthal and Wilt 1987). To investigate whether the size increase of G10 mRNA that occurs during maturation was due to adenylation, we compared the length of the poly(A) tail of G10 mRNA from ovarian material (oocytes) and eggs. Poly $(\mathrm{A})^{+}$RNA from these cells was hybridized to oligo(dT); the RNA-DNA hybrids were then digested with RNase $\mathrm{H}$ and analyzed on a Northern gel blot (Fig. 2). Following RNase $H$ treatment of ovarian RNA, the size of G10 mRNA decreased from about 850 nucleotides to about 760 nucleotides, indicating a poly(A) tail length of nearly 90 residues. RNase $\mathrm{H}$ digestion of egg RNA caused G10 mRNA to decrease in size from about 960 nucleotides (mean length, range 850-1070 nucleotides) to about 760 nucleotides, a difference of $\sim 200$ residues. This shows that during oocyte maturation, G10 mRNA becomes hyperadenylated, which is concomitant with its mobilization into polysomes.

The complete sequence of G10 RNA, and the putative amino acid sequence of the protein it encodes, is shown in Figure 3. The predicted composition of 144 amino acids, corresponding to the longest open reading frame, agrees with the in vitro translation product of this RNA, which is $18.4 \mathrm{kD}$ (Swiderski and Richter 1988). Upstream of the putative initiation codon are two additional AUG sequences (nucleotides 30-32 and 82-84), both of which are followed by termination codons (nucleotides 36-38 and 97-99, respectively). Based on context, the AUG most likely to be used in vivo is the third AUG codon (Kozak 1986). Although a comparison of the amino acid sequence of G10 protein with those of other proteins compiled in the National Biomedical Resource Foundation-Protein Identification Resource Data Base (Release 12.0) did not reveal any significant homologies, two features of the G10 protein should be mentioned. First, a hydrophilic region encompassing amino acid residues 2-10 (corresponding to nucleotide residues $200-226$ ) is reminiscent of a nuclear targeting sequence (Dingwall and Laskey 1986), in which positively charged residues tend to be flanked with the helix-breaking residues glycine or proline (Burglin and DeRobertis 1987). Second, amnio acid residues 102-119 (corresponding to nucleotide residues 500-553) fit exactly a consensus zinc-binding finger (Payre and Vincent 1988), which might indicate that G10 interacts with DNA. At present, however, we do not know the in vivo function of these regions in the G10 protein.

\section{Injection of G10 mRNA into oocytes}

Our next goal was to identify the sequence(s) of G10 mRNA that regulates polyadenylation and/or transla- 
McGrew et al.

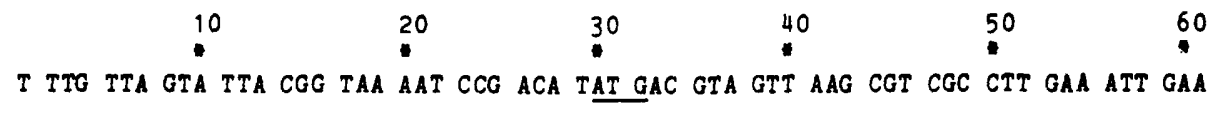

$\begin{array}{llllll}70 & 80 & 90 & 100 & 110 & 120\end{array}$

AAG ACC GTG TGG CGC GTG GGA TGA TTA GCA TAC AGT GAC TGG GCG CGT ACA CAG GAA GCG

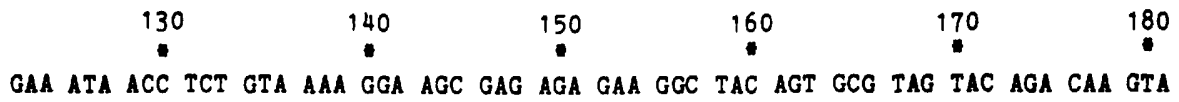

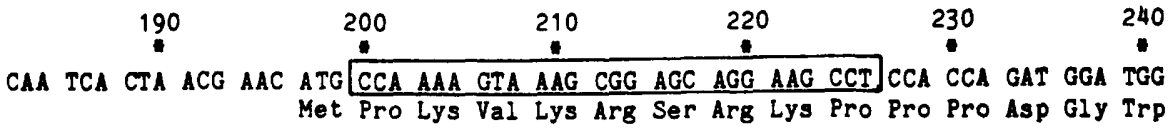

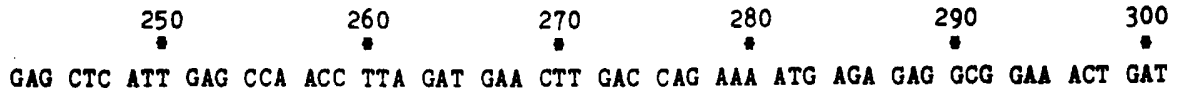
Glu Leu Ile Glu Pro Thr Leu Asp Glu Leu Asp Gin Lys Met Arg Glu Ala Glu Thr Asp

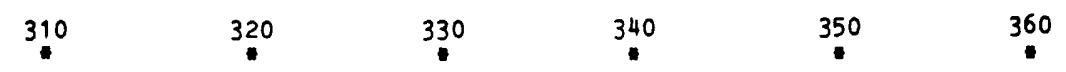

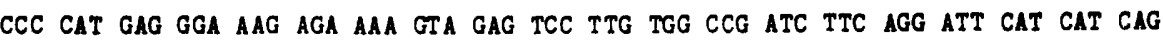
Pro H1s Glu Gly Lys Arg Lys Val Glu Ser Leu Trp Pro Ile Phe Arg Ile His H1s Gin

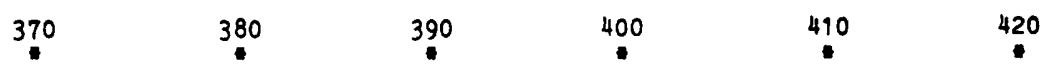

MAA ACT CGC TAT ATC TTT GAC CTA TTT TAC AAG AGA AAA GCC ATC AGC AGA GAG CTA TAC Lys Thr Arg Tyr Ile Phe Asp Leu Phe Tyr Lys Arg Lys Ala Ile Ser Arg Glu Leu Tyr

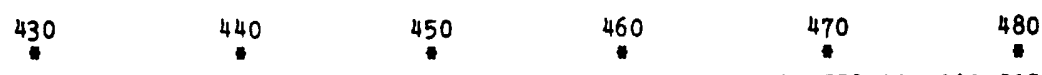

GAC TAC TGC ATC AGG GAA GGA TAT GCT GAT AAG AAC CTC ATT GCA MAA TGG AAA AA CAG Asp Tyr Cys Ile Arg Glu Gly Tyr Ala Asp Lys Asn Leu Ile Ala Lys Trp Lys Lys Gln

$\begin{array}{llllll}490 & 500 & 510 & 520 & 530 & 540\end{array}$

GOC TAT GAA AAC CTG TGT TGC CTG CGC TGT ATA CAG ACC AGA GAC ACC AAC TTT GGG ACC Gly Tyr Glu Asn Leu Cys Cys Leu Arg Cys Ile Gin Thr Arg Asp Thr Asn Phe Gly Thr

$550 \quad 560 \quad 570 \quad 580 \quad 590 \quad 600$

AAT TGT ATT TGC AGG GTC CCA AAA ACC AAA CTG GAA GTG GGG AGG ATC ATT GAG TGC ACA Asn Cys Ile Cys Arg Val Pro Lys Thr Lys Leu Glu Val Gly Arg Ile Ile Glu Cys Thr

$610 \quad 620 \quad 630 \quad 640 \quad 650 \quad 600$

CAC TGT GGC TGC AGA GGA TGC TCT GGA TAA AGA ATG GGT CCG ATT CTA TTT TTG ACT TCT

H1s Cys Gly Cys Arg Gly Cys Ser Gly -..

$\begin{array}{llllll}670 & 680 & 690 & 700 & 710 & 720\end{array}$

GGA GTA TTT TAA GGC CGG CGA CTG AAA TTG TGT TTT GAA AGT TTA TCT ATA ACG TCA CGT

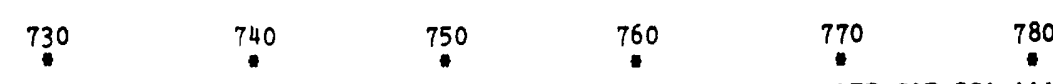

CAT TTT AAT ATT ATT TGT GTT TTT TAT AAA GGT GTA ATA AAC ATG ACA TTT CAT GGA AAA

790

AMA AAM AAA AAR AAA A

Figure 3. DNA sequence and derived amino acid sequence of G10 cDNA. Two upstream AUG codons are indicated by the single underlines. A putative nuclear targeting signal, encompassing amino acid residues $2-10$ is boxed. A consensus zinc-binding finger is denoted by a double line. The consensus nuclear polyadenylation hexamer is denoted by a bold line. 
tion during oocyte maturation. To do this, G10 cDNA, which had been cloned into the SP6 promoter-containing vector pMW005 (Dworkin and Dworkin-Rastl 1985) by oligo(dG) : oligo(dC) tailing, was used as a template for in vitro RNA synthesis. The ${ }^{32} \mathrm{P}$-labeled run-off transcripts from pG10 linearized at the HindIII site (Fig. 4A) were injected into oocytes, which were then induced to mature with progesterone. Upon maturation, the RNA was extracted and analyzed on urea-polyacrylamide gels followed by autoradiography. In these experiments, SP6-derived G10 mRNA was not adenylated (data not shown), nor was it mobilized into polysomes (Swiderski and Richter 1988). Because the injected G10 mRNA might be refractory to endogenous regulatory controls due to extraneous vector and cloning sequences, the same pG10 run-off transcripts were incubated with oligo(dT) and RNase $\mathrm{H}$, which removed sequences downstream of the $3^{\prime}$-untranslated region including most, if not all, of the poly(A) tail. When injected into oocytes this RNA, G10/dT, increased in size from 850 nucleotides to about 945 nucleotides (mean length; range 890-1000 nucleotides) in mature oocytes (Fig. 4B). As these added nucleotides were sensitive to treatment with oligo/dT) and RNase H (Fig. 4B), we infer that injected G10/dT mRNA was adenylated with nearly 100 residues during maturation. To assess whether this polyadenylation was specific for G10/dT mRNA, we performed an identical experiment with SP6derived Xenopus $\beta$-globin mRNA, which was also deadenylated prior to injection (globin/dT). This transcript was not adenylated during oocyte maturation (Fig. 4B), which demonstrates that this reaction occurs only on specific mRNA substrates.

To define the sequence in G10 mRNA mediating this maturation-specific polyadenylation, we linearized pG10 at either the NaeI or SspI sites (Fig. 4A), synthesized radiolabeled run-off transcripts, and injected them into oocytes that were then incubated with progesterone. Neither deletion mutant was adenylated (Fig. 4B|, suggesting that the polyadenylation signal resides in the 3' terminal 50 nucleotides of G10 mRNA (Fig. 4A).

Because the injected G10/dT transcripts were polyadenylated during maturation, we wished to know whether they were also assembled into polysomes at this time. Therefore, ${ }^{32}$ P-labeled G10/dT mRNA was injected into oocytes that were subsequently treated with progesterone, followed by preparation of polysome and supernatant fractions as described in Figure 1. The distribution of G10/dT mRNA between these two fractions was analyzed by gel electrophoresis and autoradiography.

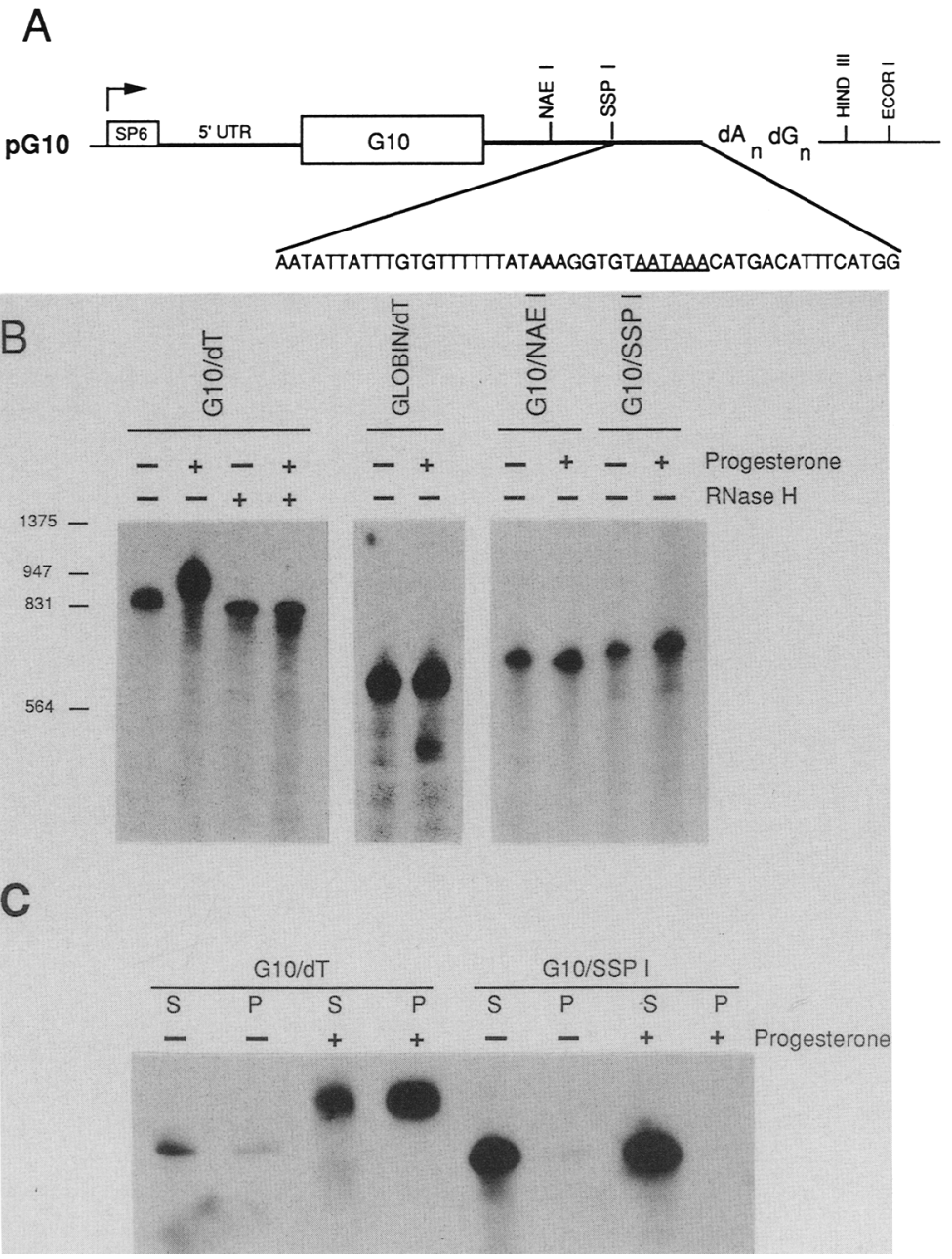

Figure 4. Size and polysomal distribution of injected G10 mRNA. $(A)$ Diagram of the SP6 plasmid containing the entire G10 cDNA. $(B)$ SP6-derived, radiolabeled deadenylated G10 RNA (G10/dT), deadenylated globin RNA (globin/dT), G10 RNA synthesized from DNA linearized at the NaeI site (G10/NaeI), and G10 RNA synthesized from DNA linearized at the $S s p I$ site (G10/SspI) were injected into stage- 6 oocytes that were subsequently incubated in the absence or presence of progesterone. Following maturation, the RNA was extracted from all oocytes and analyzed on a polyacrylamide-urea gel followed by autoradiography. The RNA from oocytes injected with G10/dT mRNA also was hybridized to oligo(dT) and treated with RNase $\mathrm{H}$ prior to electrophoresis. Size markers from $\lambda$ DNA digested with HindIII and EcoRI are noted. $(C) \mathrm{G10} / \mathrm{dT}$ and G10/SspI RNAs, synthesized as described in $B$, were injected into oocytes, some of which were subsequently treated with progesterone. Following maturation, the oocytes were homogenized and centrifuged through $35 \%$ sucrose as described in Fig. 1. The injected RNA sedimenting with the polysomal pellet (P) or postpolysomal supernatant (S) was visualized by autoradiography. 
Densitometric scanning of the autoradiograph shown in Figure $4 \mathrm{C}$ demonstrated that this transcript was $18 \%$ polysomal in control oocytes and nearly $70 \%$ polysomal in mature oocytes. This is consistent with the polysomal distribution of endogenous G10 mRNA (Fig. 1A). We also assessed whether G10/SspI mRNA, which was not polyadenylated during maturation, still retained the capacity to assemble into polysomes. This message was not translated in either control or mature oocytes (Fig. $4 \mathrm{C}$ ), which indicates that a sequence in the $3^{\prime}$ terminal 50 nucleotides is necessary for both polyadenylation and translation of G10 mRNA.

\section{A 50-base cis element of G10 mRNA is sufficient for polyadenylation and translation}

We have investigated whether the 50-base cis sequence of G10 mRNA is sufficient to mediate maturation-specific polyadenylation and translation of another mRNA that does not normally undergo these processes. The SspI-EcoRI fragment of pG10 (Fig. 4A), was fused to a Xenopus $\beta$-globin cDNA that was truncated at the
BstEII site (pXBG10, Fig. 5A). This cDNA was linearized at the EcoRI site (Fig. 5A); a radiolabeled run-off transcript was generated, deadenylated with oligo(dT) and RNase $H$, and injected into oocytes that were induced to mature with progesterone. This RNA increased in size from 790 nucleotides to 1005 nucleotides during maturation (Fig. 5B). Because the increase in size was sensitive to treatment with oligo(dT) and RNase $\mathrm{H}$ (Fig. 5B), we infer that this chimeric RNA was adenylated with about 215 residues. We also should note that G10 mRNA, as well as chimeric RNAs that include the G10 3 '-untranslated region migrate aberrantly slowly in our urea-acrylamide gels; the reason for this is unclear, but could be due to secondary structure anomalies.

Polyadenylation of G10 mRNA at maturation normally takes place on a transcript that already contains a poly(A) tail. Our injection experiments, however, have used RNAs that lack poly(A). To test whether an injected RNA can be polyadenylated if it contains an existing poly(A) tail, we treated a run-off XBG10 RNA with oligo $(\mathrm{dC})$ and RNase $\mathrm{H}$, resulting in an mRNA containing 20 adenylate residues at its $3^{\prime}$ terminus [the
Figure 5. Size and polysomal distribution of injected G10/globin chimeric RNA. (A) Diagram of pXBG10, in which the Xenopus $\beta$-globin $5^{\prime}$-untranslated region (5' UTR) and coding sequence, terminated by a BstEII cleavage site, are joined to the the 3' UTR of G10, whose 5' boundary is an SspI site. $(B)$ Radiolabeled XBG10 RNA, treated with either oligo/dT) and RNase $\mathrm{H}$ (XBG10/dT), or oligo(dC) and RNase $\mathrm{H}$ (XBG10/dC), was injected into oocytes, some of which were matured with progesterone. The RNA was then extracted and analyzed by electrophoresis and autoradiography. RNA from XBG10/dT mRNA injected oocytes was also treated with oligo(dT) and RNase $\mathrm{H}$ prior to electrophoresis. $(C)$ Oocytes were injected with radiolabeled globin RNA synthesized from a template linearized at the BstEII site and XBG10/dT mRNA and their polysomal distributions, before and after maturation, were determined as described in Fig. 4.
A pXBG10

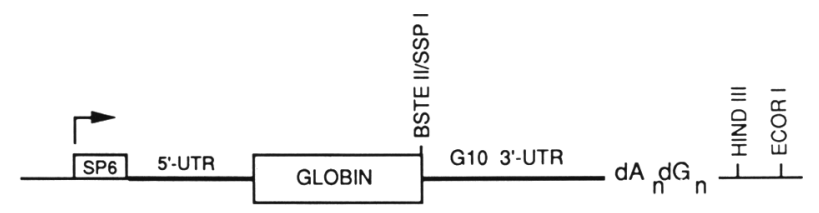

B

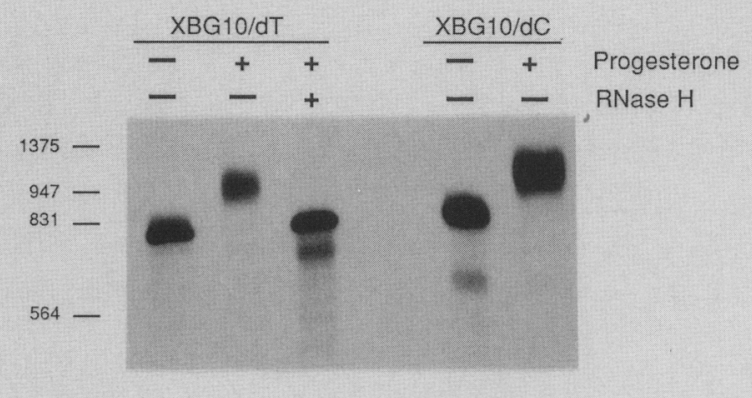

C

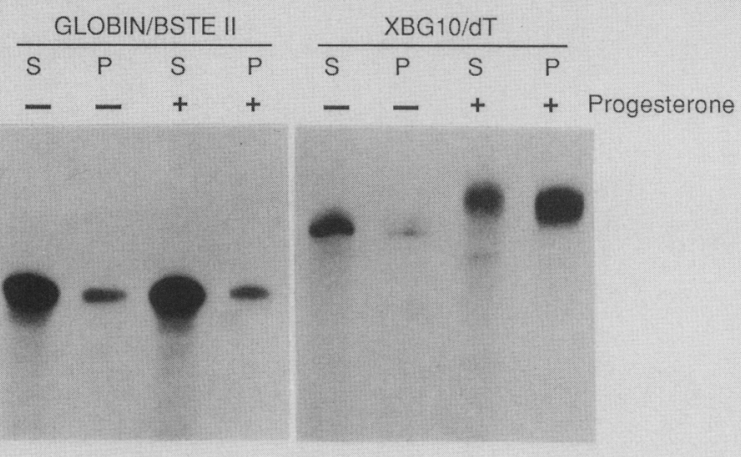


length of the poly(A) tail in XBG10]. Upon injection and subsequent maturation, this RNA was polyadenylated with an additional 245 residues (Fig. 5B), demonstrating that polyadenylated as well as nonpolyadenylated substrates are used efficiently in this reaction.

We determined whether the chimeric XBG10 mRNA, which is polyadenylated during oocyte maturation, also assembles into polysomes. First, however, the polysomal distribution of the control mRNA, Xenopus $\beta$ globin mRNA, truncated at the BstEII site, was examined. This RNA was neither polyadenylated nor recruited into polysomes following oocyte maturation (Fig. 5C). In contrast, XBG10/dT mRNA was not only polyadenylated, but also assembled into polysomes at this time $17 \%$ polysomal in control oocytes versus $70 \%$ polysomal in mature oocytes). These data were confirmed by experiments in which oocytes injected with XBG10/dT mRNA, which encodes globin, were also injected with $\left[{ }^{35} \mathrm{~S}\right]$ methionine. Newly synthesized protein that corresponds to the size of globin was observed in mature, but not control oocytes (data not shown). Therefore, these data show that the 50-base element of G10 mRNA is not only necessary, but also sufficient for polyadenylation and translation during maturation.

\section{Two sequences within the 50-base element are} required for polyadenylation

A comparison of the $3^{\prime}$-untranslated region of G10 mRNA with those of several other transcripts that undergo poly(A) elongation during early development reveals two conserved regions (Fig. 6). The first is the hexanucleotide AAUAAA, a nuclear pre-mRNA cleavage and polyadenylation signal that is present in virtually all polyadenylated mRNAs. The second region consists of a U-rich sequence followed by an AU dinucleotide 4-13 bases upstream of the hexanucleotide. To assess whether these sequences, or others, are important for polyadenylation and translation, three additional radiolabeled mutant SP6-derived RNAs were constructed.

The first transcript, XBG10 $4763-797$, consists of the 3 '-untranslated region of G10 mRNA truncated immediately after the AAUAAA hexanucleotide fused to Xenopus $\beta$-globin coding sequences (Fig. $7 \mathrm{~A}_{\text {; }}$ mutants are numbered according to the nucleotide sequence shown in Fig. 3). This transcript was both polyadenylated (Fig. 7B) and recruited into polysomes (Fig. 7C) during maturation. Therefore, sequences downstream of the hexanucleotide are not necessary for these processess. The mutant mRNA XBG10 $5757-797$ lacks the hexanucleotide and all downstream G10 sequences (Fig. 7A). This transcript was neither polyadenylated (Fig. $7 \mathrm{~B}$ ) nor recruited for translation (Fig. 7C), which demonstrates the requirement of this sequence for these responses to maturation. The final transcript, XBG10 $\Delta 741-748$, lacks only the UUUUUUAU octanucleotide (Fig. 7A). The deletion of this sequence also inhibited polyadenylation and translation following maturation (Fig. 7B,C). These data therefore show that two sequences within the G10 mRNA 3 '-untranslated region, UUUUUUAU and AAUAAA, are both required for polyadenylation and subsequent translation.

\section{Polyadenylation is required for translation of G10 mRNA}

The data presented thus far show that the poly(A) tail of endogenous G10 mRNA increases from 90 to 200 residues in response to progesterone, that of $\mathrm{G} 10 / \mathrm{dT}$ mRNA from 0 to $\sim 95$ residues, and that of XBG10/dT mRNA from 0 to $\sim 215$ residues. This might suggest that a poly(A) tail size of $>90$ residues is sufficient for G10 mRNA translation in oocytes. To determine whether this is the case, we have added a long poly $(\mathrm{A})$ tail to XBG10 (mean length of 210 residues; range 100-325 residues|, and have examined its translation in oocytes. Figure 8 shows that $<10 \%$ of these molecules were translated in oocytes, and demonstrates that a long poly(A) tail is insufficient for translation. Following oocyte maturation, these molecules were not only further adenylated (with an additional 175 residues), but also were recruited into polysomes (by $30 \%$ ). Therefore, G10 mRNA translation is not controlled by the number of adenylate residues, but could be regulated by the dynamic process of polyadenylation.

To examine the relationship between polyadenylation and translation we attempted to uncouple these two responses to maturation by adding $3^{\prime}$-deoxyadenosine (cordycepin) to the $3^{\prime}$ terminus of XBG10/dT mRNA. This prevents the polymerization of adenylate residues

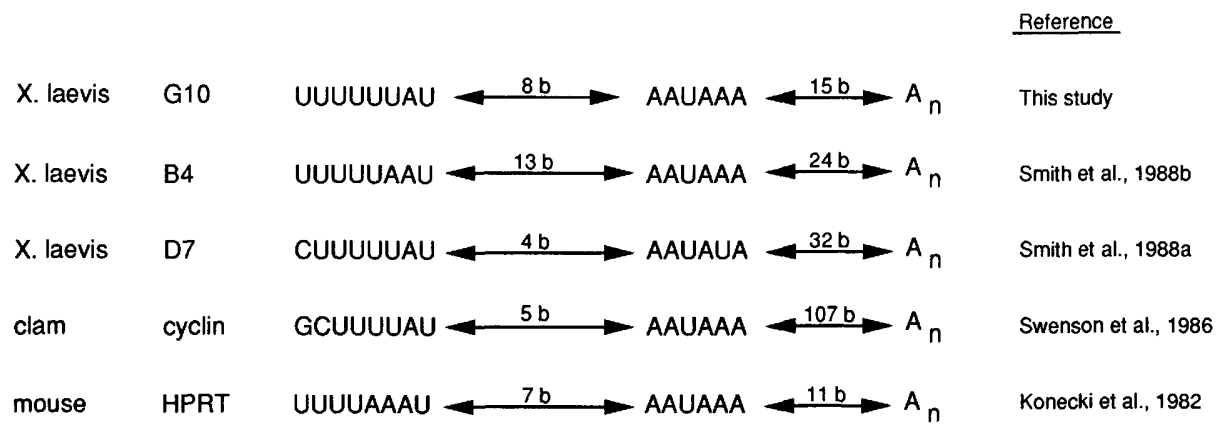

Figure 6. Sequence comparison of a portion of the $3^{\prime}$-untranslated region of several mRNAs that undergo cytoplasmic polyadenylation during early development. 
McGrew et al.

A
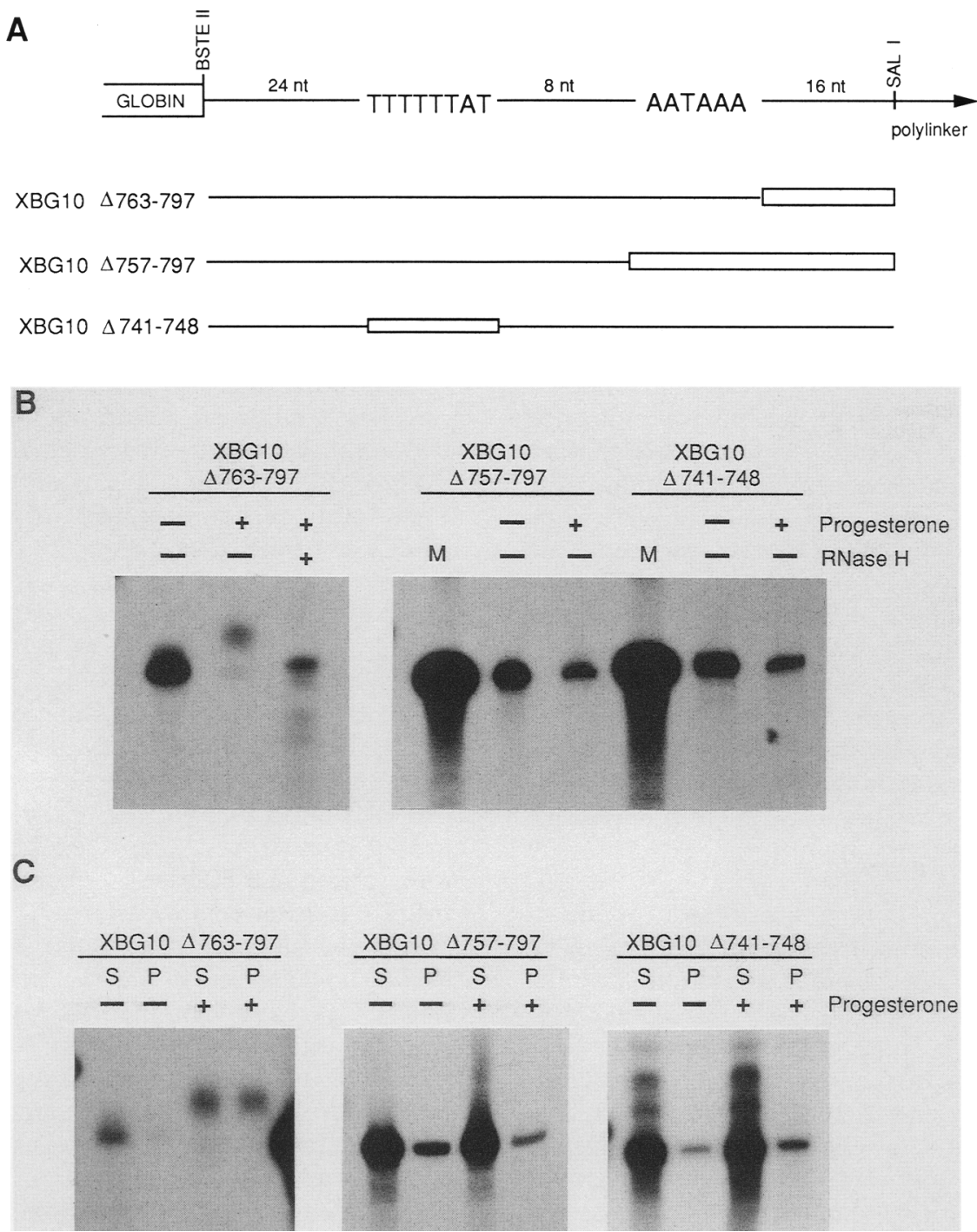

Figure 7. Size and polysomal distribution of deletion mutant mRNAs. (A) Schematic representation of the mutant XBG10 RNAs used in this study. The open boxes refer to regions that have been deleted. (B) SP6-derived, radiolabeled XBG10 $4763-797$,

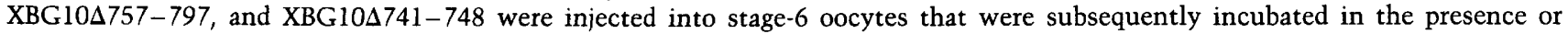
absence of progesterone. Following maturation, the RNA was extracted and analyzed by electrophoresis and autoradiography. RNA from XBG10 $463-797$ mRNA injected oocytes was also treated with oligo(dT) and RNase H prior to electrophoresis. Uninjected,

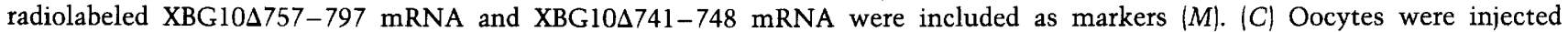

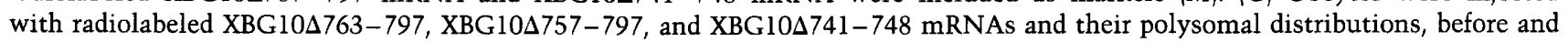
after maturation, were determined as described in Fig. 4.

to this mRNA, and permits us to test whether, upon maturation, XBG10/dT-3'-dA mRNA would be recruited into polysomes. Figure 9A shows that these transcripts were neither polyadenylated nor translated following oocyte maturation. As a control for the possible inhibitory effects of cordycepin on translation, the analog was added to adenovirus E1A 13S mRNA, which is known to be translated when injected into oocytes (Richter et al. 1988). As seen in Figure 9B, cordycepin did not inhibit translation of this mRNA. Thus, we conclude that the 50-base cis element of G10 mRNA contains a polyadenylation signal rather than a translation signal per se, and that the process of polyadenylation is required for the recruitment of this message into polysomes during maturation.

\section{Discussion}

Identification of a cis element that is required for polyadenylation and translation

In a previous study, one of our laboratories (E. DworkinRastl and M.B. Dworkin) isolated cDNA clones for mRNAs that enter polysomes during Xenopus oocyte maturation and/or soon after fertilization (Dworkin et al. 1985). We have used a cDNA clone for one of these transcripts, termed G10, and have shown that coinci- 


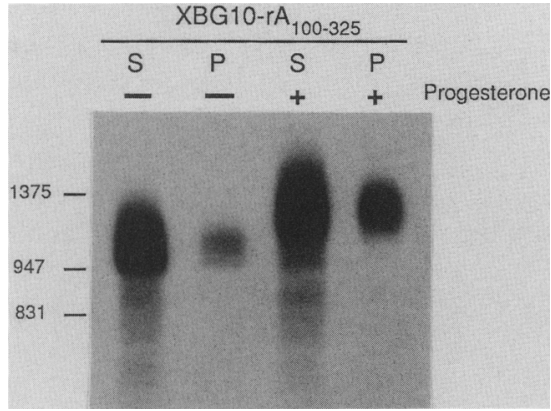

Figure 8. Polysomal distribution of XBG10 RNA that contains a long poly(A) tail. Radiolabeled XBG10/dT mRNA was incubated with poly(A) polymerase and ATP. The resulting RNA (XBG10-rA $\mathrm{A}_{100-325}$ ), containing 100-325 adenylate residues, was injected into oocytes, some of which were induced to mature with progesterone. The polysomal distribution of this RNA was determined as described in Fig. 4.

dent with its translation is a lengthening of its poly $(\mathrm{A})$ tail from $\sim 90$ residues to $\sim 200$ residues. To identify the cis element that is required for maturation-specific polyadenylation and/or translation, we have synthesized wild-type and deletion mutant SP6-derived G10 mRNAs, injected them into oocytes, matured the oocytes in vitro by treatment with progesterone, and assessed whether they become polyadenylated and enter polysomes. Wild-type G10 mRNA, but not mutant transcripts lacking the $3^{\prime}$ terminal 50 nucleotides, is polyadenylated and recruited for translation at maturation. When this 50 -base sequence was linked to a frog $\beta$ globin mRNA lacking the $3^{\prime}$-untranslated region, the polyadenylation and polysome recruitment phenotypes of G10 mRNA were conferred to this transcript. Thus, a sequence within this 50-base region is necessary and sufficient for polyadenylation and translational recruitment during maturation.

This 50-base sequence includes the canonical AAUAAA motif that is important for positioning the cleavage site of nuclear pre-mRNAs that are subsequently polyadenylated (for review, see Nevins 1983; Humphrey and Proudfoot 1988). Because this hexamer is present on nearly all cytoplasmic poly $(\mathrm{A})^{+}$mRNAs, it would clearly be insufficient to direct the specific cytoplasmic polyadenylation that we report here (e.g., Figs. 1 and 4 show that actin and globin mRNAs, which contain the polyadenylation hexamer, are not adenylated at maturation). However, a nucleotide sequence comparison of the 50-base cis element of G10 with other mRNAs that undergo cytoplasmic poly(A) elongation during early development revealed the presence of a conserved octamer $5^{\prime}$ of the AAUAAA hexanucleotide (Fig. 6). To assess whether the octamer, or another sequence, was important for cytoplasmic poly(A) elongation, three mutant mRNAs were constructed in which various regions of the G10 $3^{\prime}$-untranslated region were deleted (Fig. 7). One mutant transcript (XBGl0 $763-$ 797) that contained both the polyadenylation hexamer and the octamer described above but lacked 16 bases $3^{\prime}$ of the hexamer, was polyadenylated and recruited in response to progesterone. A second mutant mRNA (XBG10 $457-797$ ), which lacked the hexamer as well as the following 16 bases, was neither polyadenylated nor recruited for translation. This demonstrates that the hexanucleotide is necessary for cytoplasmic poly $(\mathrm{A})$ elongation. A third mutant (XBG10 $741-748$ ), which lacked only the UUUUUUAU octanucleotide, was not polyadenylated or translated during maturation. Therefore, within the 50-base 3'-untranslated region of G10 mRNA are two sequences that together are necessary for polyadenylation and translation.

\section{Polyadenylation is required for translation}

Several studies have shown a strong, although not absolute, correlation between polyadenylation and translation during early development. For example, following fertilization in Spisula, several cytoplasmic RNAs become adenylated and are recruited for translation (Rosenthal et al. 1983; Rosenthal and Ruderman 1987). Similar phenomena accompany fertilization in Urechis (Rosenthal and Wilt 1986) and oocyte maturation in the mouse (Paynton et al. 1988). Conversely, other mRNAs that are deadenylated during maturation or fertilization are no longer translated (Rosenthal et al. 1983; Rosenthal and Ruderman 1987; Hyman and Wormington

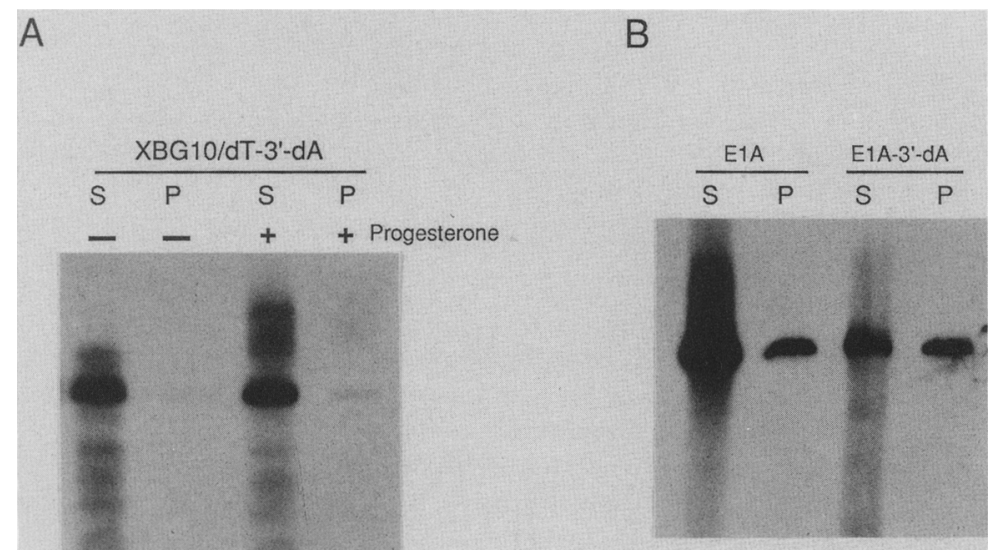

Figure 9. (A) Polysomal distribution of RNAs that contain cordycepin. Radiolabeled XBG10/dT RNA was incubated with poly $(A)$ polymerase and cordycepin (to yield XBG10/dT-3'-dA) and then injected into oocytes. The polysomal distribution of this RNA, before and after maturation, was determined as described in Fig. 4. $(B)$ Radiolabeled SP6-derived adenovirus E1A RNA was incubated in the absence (E1A) or presence of cordycepin (E1A-3'-dA) and then injected into oocytes. The polysomal distribution of this RNA was determined as described in Fig. 4. 
1988). Finally, some mRNAs do not follow this general pattern in that they are deadenylated during oocyte maturation, but enter, rather than leave polysomes (Ruderman et al. 1979; Ballantine and Woodland 1985). Taken together, these studies suggest a more than coincidental relationship between polyadenylation and translation, but whether it is one of cause and effect still remains unclear.

In our attempts to uncouple polyadenylation from translation, we added cordycepin to the $3^{\prime}$ terminus of XBG10 mRNA, thus rendering it incapable of polyadenylation. This molecule was unable to be recruited into polysomes during maturation, and establishes that, in this case, polyadenylation is necessary for translation. We also added cordycepin to XBG10-rA $100-325$ mRNA to assess whether this transcript also was unable to be recruited at maturation. Unfortunately, this message underwent some hydrolysis of the poly(A) tail, which resulted in a transcript devoid of the cordycepin. We also injected cordycepin directly into oocytes, but this, interestingly, inhibited maturation. Although one might suspect that a message with a poly(A) tail of $\sim 200$ residues (the number present on endogenous G10 mRNA in mature oocytes) might be required for translation, G10/dT mRNA contained only $\sim 90$ residues when it was translated at maturation. Therefore, these aggregate data strongly suggest that G10 mRNA translation requires the dynamic process of polyadenylation, and not merely a set number of adenylate residues. This was clearly demonstrated by the experiment in which the addition of up to 325 adenylate residues to XBG10 mRNA failed to stimulate its translation in oocytes; this message was translated, however, when further polyadenylated in response to progesterone. These results should be compared with those of other studies that show that the mere presence of a poly(A) tail can increase translational efficiency (Palatnik et al. 1984; Drummond et al. 1985; Gallili et al. 1988). These apparent discrepancies may suggest that recruitment of mRNA into polysomes (i.e., release from a block of translation) and increased translational efficiency are fundamentally different responses to polyadenylation. In the former case, many oocyte mRNAs are sequestered from the translational apparatus as assessed by their slower rate of sedimentation relative to the $80 \mathrm{~S}$ monosome. Following maturation, several of these messages become fully loaded with ribosomes and have a mean sedimentation value of $300 \mathrm{~S}$ (Richter et al. 1982). In the latter case, poly(A) might not induce mRNAs to enter polysomes, but rather could mediate the number of ribosomes on messages that already are being translated (Palatnik et al. 1984). It should also be noted that message recruitment into polysomes, and not increased translational efficiency, is responsible for the twofold increase in protein synthesis observed during oocyte maturation (Richter et al. 1982).

We estimate that oocytes contain $\sim 30 \mathrm{pg}$ of G10 mRNA, all of which is polyadenylated at maturation. However, only about $60 \%$ of this message assembles into polysomes. As such, one might speculate that a translation factor becomes rate limiting after polyadeny- lation has occurred. However, we injected about 700fold excess SP6-derived mRNA relative to endogenous G10 mRNA, yet all of this material was polyadenylated and about $70 \%$ was recruited into polysomes. Therefore, it is unlikely that a translational factor becomes rate limiting following polyadenylation. It is possible that this incomplete translational activation of G10 mRNA reflects the time at which the assays were performed. Although polyadenylation occurs immediately after nuclear membrane dissolution, polysome assembly probably continues over the next several hours. Indeed, by the 4-cell stage, G10 mRNA can be detected only in polysomes (Dworkin et al. 1985, and unpubl.).

In this study, we have shown that the recruitment of G10 mRNA into polysomes during oocyte maturation requires the process of polyadenylation. Poly(A) elongation, in turn, is mediated by a 50-base sequence element that resides in the $3^{\prime}$-untranslated region. Contained within this 50-base sequence are two elements, UUUUUUAU and AAUAAA, which are each required for polyadenylation and subsequent translation. The observation that neither element can act independently of the other suggests two possibilities for factor interaction. First, one factor, such as a sequence-specific poly(A) polymerase, might require both elements for proper binding and/or activity. This factor could always be cytoplasmic or could become cytoplasmic only after its release from the nucleus following dissolution of the nuclear envelope (germinal vesicle breakdown) at maturation. Alternatively, different factors could interact with each element; one factor that confers message specificity by binding to the UUUUUUAU sequence, and another factor, possibly a general poly(A) polymerase, that interacts with the AAUAAA sequence. Presently, we are attempting to distinguish between these possibilities.

\section{Materials and methods}

Extraction of RNA and gel blot analysis

RNA was extracted from Xenopus laevis stage-6 oocytes (Dumont 1972), embryos (staged according to Nieuwkoop and Faber 1976), or whole ovary with $p$-aminosalicylic acid (PAS), SDS, and phenol/chloroform (Kirby 1965). Poly(A)+ RNA was selected by four passages through an oligo(dT) column (type 7 , P-L Biochemicals). RNAs were resolved by electrophoresis through $1.3 \%$ agarose gels containing $2.2 \%$ formaldehyde, blotted to nitrocellulose (Thomas 1980), and probed with nicktranslated G10 or actin cDNA clones. General procedures have been described in Maniatis et al. (1982).

Poly $(\mathrm{A})^{+}$RNA was deadenylated in vitro by a modification of the procedure described by Colot and Rosbash (1982). Two micrograms of total ovary or egg RNA was incubated with $2 \mu \mathrm{g}$ of oligo(dT) $)_{12-18}$ in a reaction containing $40 \mathrm{~mm}$ Tris- $\mathrm{HCl}(\mathrm{pH} 7.5)$, $10 \mathrm{mM} \mathrm{MgCl}$, and $50 \mathrm{mM} \mathrm{KCl}$ for $15 \mathrm{~min}$ at $37^{\circ} \mathrm{C}$. One unit of RNase $\mathrm{H}$ (Promega Biotec) was added to the reaction and the incubation continued for another $30 \mathrm{~min}$ at $37^{\circ} \mathrm{C}$. The RNA was then extracted with phenol and chloroform, precipitated with ethanol, and collected by centrifugation. Approximately 1 $\mu \mathrm{g}$ of RNA from each sample was analyzed on a gel blot. 


\section{Polysome isolation}

Oocytes were defolliculated manually and were induced to mature by incubation in Barth's medium (Maniatis et al. 1982) containing $1 \mu \mathrm{g} / \mathrm{ml}$ progesterone. Maturation was detected by the presence of a white spot at the animal pole $5-8 \mathrm{hr}$ after the addition of hormone. These oocytes, and control oocytes, in pools of 10 , were homogenized in $750 \mu \mathrm{l}$ of $300 \mathrm{~mm} \mathrm{NaCl}, 20$ $\mathrm{mm}$ Tris- $\mathrm{HCl}(\mathrm{pH} 7.4), 10 \mathrm{~mm} \mathrm{MgCl}_{2}, 0.5 \%$ Nonidet P-40, 20 $\mu \mathrm{g} / \mathrm{ml}$ polyvinyl sulfate, and $4 \mathrm{mM}$ vanadyl ribonucleoside complex (Bethesda Research Laboratories) and centrifuged at $12,000 \mathrm{~g}$ for $15 \mathrm{~min}$ at $4^{\circ} \mathrm{C}$. The supernatants were layered over a step gradient of $10 \%$ sucrose $(2 \mathrm{ml})$ and $35 \%$ sucrose $(2.5 \mathrm{ml}$ ), both in polysome buffer. Polysomes were centrifuged through the sucrose cushions at $35,000 \mathrm{rpm}$ for $2 \mathrm{hr}$ at $4^{\circ} \mathrm{C}$ in a Beckman SW50.1 rotor. The RNA was extracted from the polysomal pellets by suspension in $0.5 \mathrm{ml} 4 \mathrm{M}$ guanidine isothiocyanate, $50 \mathrm{~mm}$ Tris- $\mathrm{HCl}(\mathrm{pH} 7.6), 5 \mathrm{~mm}$ EDTA, $0.5 \%$ sodium lauryl sarkosinate, and $0.1 \mathrm{M} \beta$-mercaptoethanol, followed by phenol/ chloroform extraction and ethanol precipitation. The collected ethanol precipitate was suspended in a solution of $10 \mathrm{~mm}$ Tris$\mathrm{HCl}$ ( $\mathrm{pH} 7.6), 5 \mathrm{~mm}$ EDTA, 1\% SDS followed by phenol/chloroform extraction and ethanol precipitation. The RNA in the supernatants, which were devoid of polysomes, was precipitated with 2 volumes of ethanol and then extracted with guanidine and phenol/chloroform as described above. In some cases, the postmitochondrial supernatants were adjusted to $20 \mathrm{mM}$ EDTA prior to ultracentrifugation through sucrose, which also contained $20 \mathrm{~mm}$ EDTA. The purified RNA from pellets and supernatants was suspended in equal volumes $(\sim 2 \mu \mathrm{l}$ per oocyte), and RNA yields were determined spectrophotometrically. Three oocyte equivalents were analyzed for each supernatant and pellet fraction.

\section{DNA sequencing and plasmid construction}

DNA sequencing was performed on double-stranded plasmid DNA by the dideoxy chain-termination method (Sanger 1972) using a Sequenase sequencing kit (U.S. Biochemical Corp.l, as well as by the method of Maxam and Gilbert (1980).

The plasmid pG10 (Dworkin et al. 1985) isolated from a Xenopus oocyte cDNA library, contains a 797-bp insert cloned downstream of the SP6 promoter. To construct the XBG10 fusion plasmid, a Xenopus $\beta$-globin clone (pSP64XBM, Krieg and Melton 1984) was digested with BstEII and filled-in with DNA polymerase I (Klenow fragment). This clone was then digested with EcoRI and ligated to a SspI-EcoRI fragment from pG10.

To construct mutant plasmids that contain deletions within the G10 mRNA 50-base cis element, oligonucleotides specific for each mutant sequence were synthesized. Complementary oligonucleotides containing a $5^{\prime}$ BstEII site and a 3' Sall site, were annealed at $50^{\circ} \mathrm{C}$ for $60 \mathrm{~min}$ in $0.1 \mathrm{M} \mathrm{NaCl}$ and were ligated into the BstEII and SalI sites of pSP64XBM. The plasmid pXBG10 $\Delta 763-797$ contained the oligonucleotide sequence 5'GTTACCACTAGAATATTATTTGTGTTTTTTATAAAGGTGTAATAAAG, annealed to its complement $5^{\prime}$-TCGACTTTATTACACCTTTATAAAAAACACAAATAATATTCTA GTG; plasmid pXBG10 $757-797$ contained the oligonucleotide sequence 5'-GTTACCACTAGAATATTATTTGTGTTTTTTATAGGTGTG, annealed to its complement 5'-TCGACACACCTTTATAAAAAACACAAATAATATTCTAGTG; and the plasmid pXBG10 $441-748$ contained the oligonucleotide sequence 5'-GTTACCACTAGAATATTATTTGTGAAAGGTGTAATAAACATGACATTTCATGGG, annealed to its complement 5'-TCGACCCATGAAATGTCATGTTTATTACACCTTTCAGAAATAATATTCTAGTG.

\section{In vitro transcription and oocyte injection}

The following DNA templates were used for transcription in vitro: pG10 linearized at the HindIII, NaeI, or SspI sites; pSP64XBM linearized at the PstI (in the vector, Krieg and Melton 1984) or BstEII (in coding sequence, Patient et al. 1983) sites; pXBG10 linearized at the EcoRI site; pXBG10 $4763-797$, pXBG10 $\Delta 757-797$, and pXBG10 $441-748$ linearized at the SalI site (cf. Fig. 7); and pSP13S (containing the ElA 13S mRNA coding sequence, Richter et al. 1988) linearized at the HindIII site. Transcription by SP6 polymerase was carried out essentially as described by Krieg and Melton (1984), except that the reaction mixture contained $50 \mu \mathrm{M}$ GTP, $500 \mu \mathrm{M}$ GpppG, and 60 $\mu \mathrm{Ci}$ of $\left[{ }^{32} \mathrm{P}\right] \mathrm{dCTP}(800 \mathrm{Ci} / \mathrm{mmole}$ Amersham). Following synthesis, the $3^{\prime}$ termini of several of the RNAs were removed (G10/dT, globin/dT, XBG10/dT, XBG10/dC) by RNase H digestion in the presence of either oligo(dT) or oligo(dC) as described previously. The RNA was extracted with phenol/chloroform and precipitated with ethanol.

Manually defolliculated oocytes were injected with 20-40 ng of radiolabeled RNA $\left(3 \times 10^{6} \mathrm{cpm} / \mu \mathrm{g}\right)$ and cultured in the absence or presence of of progesterone. Within $1 \mathrm{hr}$ after the appearance of a white spot at the animal pole, the oocytes were homogenized and centrifuged through sucrose cushions as described earlier. Alternatively, the RNA was extracted directly from the injected oocytes and analyzed without further treatment or after deadenylation with oligo(dT) and RNase $\mathrm{H}$.

To add cordycepin to mRNA, $5 \mu \mathrm{g}$ of radiolabeled XBG10/dT or E1A RNA was incubated in a 50- $\mu$ l reaction containing 200 $\mu M$ 3' dATP (cordycepin), $50 \mathrm{mM}$ Tris- $\mathrm{HCl}(\mathrm{pH} 8.0$ ), $10 \mathrm{~mm}$ $\mathrm{MgCl}_{2}, 50 \mu \mathrm{g} / \mathrm{ml}$ of BSA, $250 \mathrm{~mm} \mathrm{NaCl}, 1 \mathrm{~mm} \mathrm{MnCl}_{2}, 2 \mathrm{~mm}$ DTT, $1.5 \mathrm{U} / \mu \mathrm{l}$ of RNasin, and 3 units of poly(A) polymerase (Pharmacia) at $37^{\circ} \mathrm{C}$ for $20 \mathrm{~min}$. This reaction produced the RNAs XBG10-3'-dA and E1A-3'-dA. The 3' terminus of XBG10 mRNA was also modified to contain 100-325 adenylate residues (XBG10-rA $\mathrm{XA0-325}_{100}$ ) by incubation of $5 \mu \mathrm{g}$ of radiolabeled $\mathrm{XBG} 10 / \mathrm{dT}$ RNA with $50 \mu \mathrm{M}$ ATP, $50 \mathrm{~mm}$ Tris- $\mathrm{HCl}$ (pH 8.0), 10 $\mathrm{mM} \mathrm{MgCl}_{2}, 50 \mu \mathrm{g} / \mathrm{ml}$ of BSA, $250 \mathrm{mM} \mathrm{NaCl}, 1 \mathrm{mM} \mathrm{MnCl}, 2$ $\mathrm{mM}$ DTT, $1.5 \mathrm{U} / \mu \mathrm{l}$ of RNasin, and 3 units of poly(A) polymerase for $5 \mathrm{~min}$ at $37^{\circ} \mathrm{C}$. All radioactive RNAs were resolved by electrophoresis in $5 \%$ polyacrylamide $-8.3 \mathrm{M}$ urea gels, followed by autoradiography. Sizes of the transcripts were determined by comparison with $\lambda$ DNA that was digested with HindIII and EcoRI.

\section{Fusion protein construction, antiserum generation, and immunoprecipitation}

An 550-bp DdeI-HindIII fragment from pG10, filled-in at the DdeI site, was cloned into pUR290 which was cut with HpaI and HindIII (Rüther and Müller-Hill 1983). This resulted in the fusion of the amino-terminal 140 amino acids of $\beta$-galactosidase with amimo acids $22-144$ of G10. Induction and fusion protein isolation from Escherichia coli, as well as immunization protocols in rabbits have been described (Smith et al. 1988 b).

Fifty control and mature stage- 6 oocytes were injected with $\left[{ }^{35}\right.$ S $]$ methionine $\left(8 \times 10^{4} \mathrm{cpm} /\right.$ oocyte, $1200 \mathrm{Ci} / \mathrm{mmole}$, Amersham), cultured for $2 \mathrm{hr}$, and homogenized in $500 \mu \mathrm{l}$ of Barth's medium containing $0.1 \%$ Triton X-100. Following brief centrifugation to remove the yolk, the supernatant was adjusted with $1 \times$ RIPA buffer [50 mM Tris- $\mathrm{HCl}(\mathrm{pH} 7.5), 150 \mathrm{~mm} \mathrm{NaCl}, 1 \%$ deoxycholate, $1 \%$ Triton X-100, $0.1 \%$ SDS] and incubated with G10 antiserum for $2 \mathrm{hr}$ at room temperature. Protein A-Sepharose was added and incubation was continued for an additional $2 \mathrm{hr}$. The beads were then washed in $1 \times$ RIPA buffer and the G10 protein was eluted by boiling in SDS gel loading buffer and 
was analyzed by SDS-15\% polyacrylamide gel electrophoresis and autoradiography. In a similar experiment, $\left[{ }^{35} \mathrm{~S}\right]$ methioninelabeled reticulocyte lysate synthesized G10 protein was immunoprecipitated with G10 antiserum and analyzed as described above.

\section{Acknowledgments}

We thank A. Shrutkowski for technical assistance and J. Goodchild for synthesizing oligonucleotides. This work was supported by grants from the National Institutes of Health [CA40189), the National Science Foundation (DCB8719300), and the American Cancer Society, Massachusetts Division (Cancer Research Scholar Award) awarded to J.D.R.

\section{References}

Adamson, E.D. and H.R. Woodland. 1977. Changes in the rate of histone synthesis during oocyte maturation and very early development of Xenopus laevis. Dev. Biol. 57: 136149.

Asselbergs, F.A.M., W.J. Van Venrooij, and H. Bloemendal. 1979. Messenger RNA competition in living Xenopus oocytes. Eur. J. Biochem. 94: 249-254.

Audet, R.G., J. Goodchild, and J.D. Richter. 1987. Eukaryotic initiation factor $4 \mathrm{~A}$ stimulates translation in microinjected Xenopus oocytes. Dev. Biol. 121: 58-68.

Ballantine, J.E.M. and H.R. Woodland. 1985. Polyadenylation of histone mRNA in Xenopus oocytes and embryos. FEBS Lett. 180: 224-228

Baum, E.Z., L.E. Hyman, and W.M. Wormington. 1988. Posttranslational control of ribosomal protein $\mathrm{Ll}$ accumulation in Xenopus oocytes. Dev. Biol. 126: 141-149.

Burglin, T.R. and E.M. DeRobertis. 1987. The nuclear migration signal of Xenopus laevis nucleoplasmin. EMBO $J$. 6: $2617-2625$.

Colin, A.M., B.D. Brown, J.N. Dholakia, C.L. Woodley, A.J. Wahba, and M.B. Hille. 1987. Evidence for simultaneous derepression of messenger RNA and the guanine nucleotide exchange factor in fertilized sea urchin eggs. Dev. Biol. 123: 354-363.

Colot, H.V. and M. Rosbash. 1982. Behavior of individual maternal $\mathrm{pA}^{+}$RNAs during embryogenesis of Xenopus laevis. Dev. Biol. 94: 79-86.

Crawford, D.R. and J.R. Richter. 1987. An RNA-binding protein from Xenopus oocytes is associated with specific message sequences. Development 101: 741-749.

Davidson, E.H. 1986. Gene activity in early development. Academic Press, New York.

Dingwall, C. and R.A. Laskey. 1986. Protein import into the cell nucleus. Annu. Rev. Cell Biol. 2: 367-391.

Drummond, D.R., J. Armstrong, and A. Colman. 1985. The effect of capping and polyadenylation on the stability, movement, and translation of synthetic messenger RNAs in Xenopus oocytes. Nucleic Acids Res. 13: 7375-7394.

Dumont, J.N. 1972. Oogenesis in Xenopus laevis (Daudin): I. Stages of oocyte development in laboratory maintained animals. J. Morphol. 136: 153-180.

Dworkin, M.B. and E. Dworkin-Rastl. 1985. Changes in RNA titers and polyadenylation during oogenesis and oocyte maturation in Xenopus laevis. Dev. Biol. 112: 451-457.

Dworkin, M.B., A. Shrutkowski, and E. Dworkin-Rastl. 1985. Mobilization of specific maternal RNA species into polysomes after fertilization in Xenopus laevis. Proc. Natl. Acad. Sci. 82: 7636-7640.

Flynn, J.M. and H.R. Woodland. 1980. The synthesis of histone
H1 during early amphibian development. Dev. Biol. 75: $222-230$.

Galili, G., E.E. Kawata, L.D. Smith, and B.A. Larkins. 1988. Role of the $3^{\prime}$-poly(A) sequence in translational regulation of mRNAs in Xenopus laevis oocytes. J. Biol. Chem. 263: 5764-5770.

Grainger, J.L. and M.M. Winkler. 1987. Fertilization triggers unmasking of maternal mRNAs in sea urchin eggs. Mol. Cell. Biol. 7: 3947-3954.

Huang, W.I., L.H. Hansen, W.C. Merrick, and R. Jagus. 1987. Inhibitor of eukaryotic initiation factor $4 \mathrm{~F}$ activity in unfertilized sea urchin eggs. Proc. Natl. Acad. Sci. 84: 63596363.

Huarte, J., D. Belin, A. Vassalli, S. Strickland, and J.-D. Vassalli. 1987. Meiotic maturation of mouse oocytes triggers the translation and polyadenylation of dormant tissue-type plasminogin activator mRNA. Genes Dev, 1: 1201-1211.

Humphrey, T. and N.J. Proudfoot. 1988. A beginning to the biochemistry of polyadenylation. Trends Genet. 4: 243-245.

Hyman, L.E. and W.M. Wormington. 1988. Translational inactivation of ribosomal protein mRNAs during Xenopus oocyte maturation. Genes Dev. 2: 598-605.

Jenkins, N.A., J.F. Kaumeyer, E.M. Young, and R.A. Raff. 1978. A test for masked message: The template activity of messenger ribonucleoprotein particles isolated from sea urchin eggs. Dev. Biol. 63: 279-298.

Kick, D., P. Barrett, A. Cummings, and J. Sommerville. 1987. Phosphorylation of a $60 \mathrm{kD}$ polypeptide from Xenopus oocytes blocks messenger RNA translation. Nucleic Acids Res. 15: 4099-4109.

Kirby, K.S. 1965. Isolation and characterization of ribosomal ribonucleic acid. Biochem. J. 96: 266-269.

Konecki, D.S., J. Brennand, J.C. Fuscoe, C.T. Caskey, and A.C. Chinai. 1982. Hypoxanthine-guanine phosphoribosyltransferase genes of mouse and Chinese hamster: Construction and sequence analysis of cDNA recombinants. Nucleic Acids Res. 10: 6763-6775.

Kozak, M. 1986. Point mutants define a sequence flanking the AUG initiator codon that modulates translation by eukaryotic ribosomes. Cell 44: 283-292.

Krieg, P.A. and D.A. Melton. 1984. Functional messenger RNAs are produced by SP6 in vitro transcription of cloned cDNAs. Nucleic Acids Res. 12: 7057-7070.

Laskey, R.A., A.D. Mills, J.B. Gurdon, and G.A. Partington. 1977. Protein synthesis in oocytes of Xenopus laevis is not regulated by the supply of messenger RNA. Cell 11:345351.

Lee, G., R. Hynes, and M. Kirschner. 1984. Temporal and spatial regulation of fibronectin in early Xenopus development. Cell 36: 729-740.

Maniatis, T., E.F. Fritsch, and J. Sambrook. 1982. Molecular cloning: A laboratory manual. Cold Spring Harbor Laboratory, Cold Spring Harbor, New York.

Maxam, A.M. and W. Gilbert. 1980. Sequencing end-labeled DNA with base-specific chemical cleavages. Methods Enzymol. 65: 499-560.

Nevins, J.R. 1983. The pathway of eukaryotic mRNA formation. Annu. Rev. Biochem. 52: 441-466.

Nieuwkoop, P.D. and J. Faber. 1956. Normal table of Xenopus laevis (Daudin). North Holland Publishing Company, Amsterdam.

Palatnik, C.M., C. Wilkins, and A. Jacobson. 1984. Translational control during early Dictyostelium development: Possible involvement of poly(A) sequences. Cell 36: 10171025.

Patient, R.K., R. Harris, M.E. Walmsley, and J.G. Williams. 
1983. The complete nucleotide sequence of the major adult $\beta$-globin gene of Xenopus laevis. J. Biol. Chem. 258: 85218523.

Paynton, B.V., R. Rempel, and R. Bachvarova. 1988. Changes in state of adenylation and time course of degradation of maternal mRNAs during oocyte maturation and early embryonic development in the mouse. Dev. Biol. 129: 304-314.

Payre, F. and A. Vincent. 1988. Finger proteins and DNA-specific recognition: Distinct patterns of conserved amino acids suggest different evolutionary modes. FEBS Lett. 234: 245250.

Richter, J.D. 1987. Molecular mechanisms of translational control during the early development of Xenopus laevis. In Translational regulation of gene expression (ed. J. Ilan), pp. 111-139. Plenum Publishing Company, New York.

Richter, J.D. and L.D. Smith. 1981. Differential capacity for translation and lack of competition between mRNAs that segregate to free and membrane-bound polysomes. Cell 27: 183-191.

1984. Reversible inhibition of translation by Xenopus oocyte-specific proteins. Nature 309: 378-380.

Richter, J.D., W.J. Wasserman, and L.D. Smith. 1982. The mechanism for increased protein synthesis during Xenopus oocyte maturation. Dev. Biol. 89: 159-167.

Richter, J.D., J.M. Slavicek, J.F. Schneider, and N.C. Jones. 1988. Heterogeneity of adenovirus type 5 ElA proteins: Multiple serine phosphorylations induce slow-migrating electrophoretic variants but do not affect E1A-induced transcriptional activation or transformation. J. Virol. 62: 19481955.

Rickles, R.J., A.L. Darrow, and S. Strickland. 1988. Molecular cloning of complementary DNA to mouse tissue plasminogen activator mRNA and its expression during F9 teratocarcinoma cell differentiation. J. Biol. Chem. 263: 15631569.

Rosenthal, E.T. and F.H. Wilt. 1986. Patterns of maternal messenger RNA accumulation and adenylation during oogenesis in Urechis caupo. Dev. Biol. 117: 55-63.

- 1987. Selective messenger RNA translation in marine invertebrate oocytes, eggs, and zygotes. In Translational regulation of gene expression (ed. J. Ilan), pp. 87-110. Plenum Publishing Company, New York.

Rosenthal, E.T. and J.V. Ruderman. 1987. Widespread changes in the translation and adenylation of maternal messenger RNAs following fertilization of Spisula oocytes. Dev. Biol. 121: $237-246$.

Rosenthal, E.T., T.R. Tansey, and J.V. Ruderman. 1983. Sequence-specific adenylations and deadenylations accompany changes in the translation of maternal messenger RNA after fertilization of Spisula oocytes. I. Mol. Biol. 166: 309327.

Ruderman, J.V., H.R. Woodland, and E.A. Sturgess. 1979. Modulations of histone messenger RNA during the early development of Xenopus laevis. Dev. Biol. 71: 71-82.

Rüther, U. and B. Müller-Hill. 1983. Easy identification of cDNA clones. EMBO J. 2: 1791-1794.

Sagata, N., M. Oskarsson, T. Copeland, J. Brumbaugh, and G.F. Vande Woude. 1988. Function of c-mos proto-oncogene product in meiotic maturation in Xenopus oocytes. Nature 335: 519-525.

Sanger, F., S. Nicklen, and A.R. Coulson. 1977. DNA sequencing with chain-terminating inhibitors. Proc. Natl. Acad. Sci. 74: 5463-5467.

Smith, L.D. and J.D. Richter. 1985. Synthesis, accumulation, and utilization of maternal macromolecules during oogenesis and oocyte maturation. In Biology of fertilization. (eds. A. Metz and A. Monroy), pp. 141-188. Academic Press New York.

Smith, R.C., M.B. Dworkin, and E. Dworkin-Rastl. 1988a. Destruction of a translationally controlled mRNA in Xenopus oocytes delays progesterone-induced maturation. Genes Dev. 2: 1296-1306.

Smith, R.C, E. Dworkin-Rastl, and M.B. Dworkin. 1988b. Expression of a histone H1-like protein is restricted to early Xenopus development. Genes Dev. 2: 1284-1295.

Spirin, A.S. 1969. Informosomes. Eur. I. Biochem. 10: 20-35.

Stick, R. and P. Hausen. 1985. Changes in the nuclear lamina composition during early development of Xenopus laevis. Cell 41: 191-200.

Swenson, K.I., K.M. Farrell, and J.V. Ruderman. 1986. The clam embryo protein cyclin $A$ induces entry into $M$ phase and resumption of meiosis in Xenopus oocytes. Cell 47: 861870.

Swiderski, R.E. and J.D. Richter. 1988. Photocrosslinking of proteins to maternal mRNA in Xenopus oocytes. Dev. Biol. 128: 349-358.

Thomas, P.S. 1980. Hybridization of denatured RNA and small DNA fragments transferred to nitrocellulose. Proc. Natl. Acad. Sci. 77: 5201-5205.

Woodland, H.R., J.M. Flynn, and A.J. Wyllie. 1979. Utilization of stored mRNA in Xenopus embryo and its replacement by newly synthesized transcripts: Histone $\mathrm{H} 1$ synthesis using interspecies hybrids. Cell 18: 165-171. 


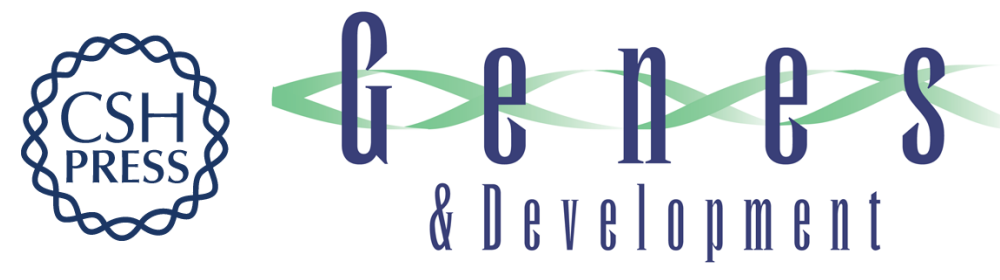

\section{Poly(A) elongation during Xenopus oocyte maturation is required for translational recruitment and is mediated by a short sequence element.}

L L McGrew, E Dworkin-Rastl, M B Dworkin, et al.

Genes Dev. 1989, 3:

Access the most recent version at doi:10.1101/gad.3.6.803

References This article cites 55 articles, 15 of which can be accessed free at: http://genesdev.cshlp.org/content/3/6/803.full.html\#ref-list-1

License

Email Alerting Service

Receive free email alerts when new articles cite this article - sign up in the box at the top right corner of the article or click here.

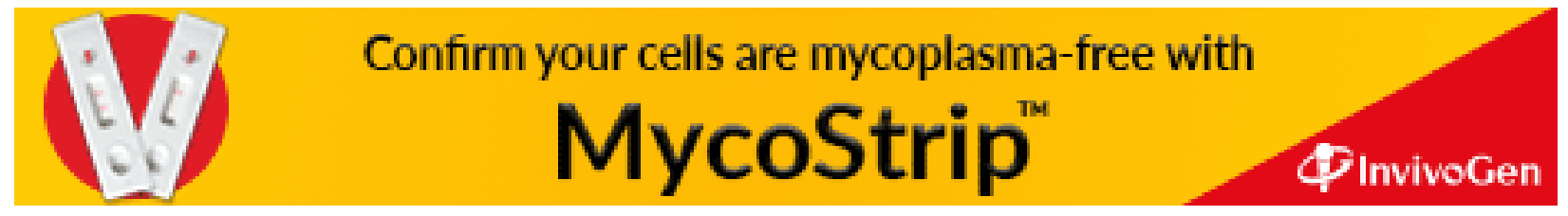

